\title{
Electronic Health Records: Then, Now, and in the Future
}

R. S. Evans

Intermountain Healthcare \& Biomedical Informatics, University of Utah School of Medicine, Salt

Lake City, USA

\begin{abstract}
Summary
Objectives: Describe the state of Electronic Health Records

(EHRS) in 1992 and their evolution by 2015 and where EHRs are expected to be in 25 years. Further to discuss the expectations for EHRs in 1992 and explore which of them were realized and what events accelerated or disrupted/derailed how EHRs evolved.

Methods: Literature search based on "Electronic Health Record", "Medical Record", and "Medical Chart" using Medline, Google, Wikipedia Medical, and Cochrane Libraries resulted in an initial review of 2,356 abstracts and other information in papers and books. Additional papers and books were identified through the review of references cited in the initial review.

Results: By 1992, hardware had become more affordable, powerful, and compact and the use of personal computers, local area networks, and the Internet provided faster and easier access to medical information. EHRs were initially developed and used at academic medical facilities but since most have been replaced by large vendor EHRs. While EHR use has increased and clinicians are being prepared to practice in an EHR-mediated world, technical issues have been overshadowed by procedural, professional, social, political, and especially ethical issues as well as the need for compliance with standards and information security. There have been enormous advancements that have taken place, but many of the early expectations for EHRs have not been realized and current EHRs still do not meet the needs of today's rapidly changing healthcare environment.

Conclusion: The current use of EHRs initiated by new technology would have been hard to foresee. Current and new EHR technology will help to provide international standards for interoperable applications that use health, social, economic, behavioral, and environmental data to communicate, interpret, and act intelligently upon complex healthcare information to foster precision medicine and a learning health system.
\end{abstract}

\section{Keywords}

Electronic Health Record, medical record, medical chart

Yearb Med Inform 2016;Suppl1:S48-61

http://dx.doi.org/10.15265/IYS-2016-s006

Published online May 20, 2016

\section{Introduction}

Translation of ancient Egyptian hieroglyphic inscriptions and papyri from 1,600-3,000 BC indicate the use of medical records. However, paper medical records were not steadily used until 1900-1920. Medical record, medical chart, and health record are different terms used to describe the documentation of a patient's medical history and care. In recent years, the term health record has received prominence based on the fact that a patient's medical information should include health and lifestyle information beyond just episodic medical encounters. Traditionally, health records were written on paper, maintained in folders divided into sections based on the type of note, and only one copy was available. New computer technology developed in the 1960s and 1970s laid the foundation for the development of the Electronic Heath Record (EHR). The use of EHRs has not only made patients' medical information easier to read and available from almost any location in the world, but also changed the format of health records, and thus changed health care.

Thousands of published studies report on EHRs increasing use, clinical decision support's (CDS) ability to improve or not improve the healthcare process or clinical outcomes, evaluation methods, implementation/adoption, clinical trial patient identification, numerous new applications, and unintended consequences. Information on specific studies is beyond the scope of this paper and not included. For the $25^{\text {th }}$ anniversary of the Yearbook of the International Medical Informatics Association (IMIA), this paper focuses on the overall state and use of EHRs in 1992 and how they have evolved by 2015 . This paper also discusses the expectations for EHRs in 1992 and which of these were realized, what events accelerated or disrupted/derailed EHR evolution. Finally, we will discuss the expected state of EHRs in the 25 years.

\section{State of EHRs in 1992}

Initially, EHRs were developed and used at a number of academic inpatient and outpatient medical facilities [1-10], but none contained all the information in the paper chart and most EHRs today are still a hybrid collection of computerized and paper data $[11,12]$ (Table 1). Some EHRs developed between 1971 and 1992 were developed with hierarchical or relational databases, around or added to hospital billing and scheduling systems while others such as COSTAR, PROMIS, TMR, and HELP were developed as clinical systems to help improve medical care and for use in medical research [3, 13-15]. While some EHRs were developed on minicomputers, most were initially developed on large mainframe computers and in either case had limited storage, which required the use of removable disk packs and/or tape for extra data storage, nightly downtimes for database back-up, and dedicated/wired terminals. Only a few early EHRs allowed physician entry of orders, prescriptions, and notes and data entry was through keyboards focused mostly on laboratory and medication review [16]. While usually hospital-based, many of the early EHRs had features and functionalities that are still used and important today.

As inadequacies of the paper record became increasingly more apparent in 1992 [17], the Institute of Medicine advocated a shift from a paper-based to an electronic medical record [12]. However, 
the widespread use of EHRs was delayed by high costs, data entry errors, poor initial physicians' acceptance, and lack of any real incentive. The goal of replacing the entire paper chart with an electronic record was considered problematic due to the large initial costs resulting in the view that only key data should be computerized. As a result, the EHR would complement and not replace the paper record [18]. Others also felt the costs to implement EHRs for general practices would outweigh any gains in efficiency, which also could be achieved through better use of paper records [19].

In the late 1980's and early 1990's, hardware became more affordable, powerful, and compact and the use of personal computers, local area networks, and the Internet provided faster and easier access to medical information and initiated the use of webbased EHRs [20]. The personal computer provided a mouse interface which made use easier with pull-down menus, pop-up lists, buttons, multi-page forms, and scrolling fields. Other features included help screens, control functions, audit trails, and export of data to statistical packages for analyses. An initial obstacle for EHR ease of use was the need for portable computers [21] and soon computers were being classified as laptop, palmtop, notebook, and pen-based [22].

\section{EHR Use in 1992}

Early use of EHRs also included data interchange for claims processing [23] and image scanning as a method for document capture [24]. Each of these efforts saved time by eliminating filing and retrieval of charts, photocopying, and chart location control [25]. More clinical use began when the physician workstation became the term used for personal computers integrated with EHRs that allowed access to physician notes, orders, consults, laboratory results, radiological studies, direct patient measurements, nursing assessments and notes, and patient care procedures. Workstations interfaced with tools such as drug references, clinical manuals, textbooks of medicine, literature search engines, CDS, and electronic communication [26, 27]. Data also could be represented in a variety of graphical formats
Table 1 Capabilities and use of EHRs in 1992 and 2015

\begin{tabular}{|c|c|}
\hline EHRs in1992 & State of the Art \\
\hline & $\begin{array}{l}\text { Mostly developed and used at academic centers } \\
\text { Hybrid of paper and electronic data } \\
\text { Hierarchical and relational databases } \\
\text { Based around billing and scheduling systems, some clinical systems } \\
\text { Large mainframe and minicomputers with limited data storage } \\
\text { Personal computers with graphics used as monitors } \\
\text { Data entry through keyboards and mouse } \\
\text { Used in inpatient \& outpatient facilities } \\
\text { Local area networks \& Internet, web-based } \\
\text { Admitting, pharmacy, laboratory, microbiology, surgery, radiology, respiratory therapy, infectious } \\
\text { diseases, radiology, nurse charting, physician notes/orders/consults, patient measurements, patient } \\
\text { care procedures, electrocardiogram, echocardiography } \\
\text { Image scanning } \\
\text { Paper printouts } \\
\text { Clinical Decision Support } \\
\text { Computerized Provider Order Entry } \\
\text { Drug references, clinical manuals, textbooks of medicine, literature searching } \\
\text { Physician documentation \& electronic signatures } \\
\text { Health Level Seven/IEEE P1157 } \\
\text { Universal Medical Language System } \\
\text { Medical device interfaces } \\
\text { Picture Archiving and Communication Systems (PACS) } \\
\text { Wide area networks } \\
\text { Ethical issues: data ownership, data liability, informed consent, security and privacy }\end{array}$ \\
\hline \multirow[t]{2}{*}{ EHRs in 2015} & Differences \\
\hline & $\begin{array}{l}\text { EHRs used in primary care exam rooms and by insurance companies, nursing homes, hospice, } \\
\text { homeless population, departments of corrections } \\
\text { Mostly vendor EHRs } \\
\text { Personal Health Records interfaced to EHRs } \\
\text { Intra-facility data sharing with standards more common } \\
\text { Data mapping to SMOMED \& LOINC } \\
\text { Digital pathology, mental health, external labs, e-prescribing, order-sets, family history, genetics, } \\
\text { biobanks, biosurveillance, public health } \\
\text { Increased Clinical Decision Support } \\
\text { Natural Language Processing } \\
\text { Big Data } \\
\text { Mobil devices } \\
\text { Open-source EHRs } \\
\text { Digital identities } \\
\text { Enterprise Data Warehouses; birth to death data } \\
\text { Increased EHR education } \\
\text { Infobuttons } \\
\text { Cloud computing } \\
\text { Alerts via email, pagers/cell phones } \\
\text { Copy and paste; note bloat } \\
\text { Unintentional consequences } \\
\text { Interfaces to medical libraries } \\
\text { Medical scribes } \\
\text { Technical issues overshadowed by procedural, professional, political, social and especially ethical } \\
\text { issues and the need for compliance with standards and information security } \\
\text { Significant increase in EHR related publications }\end{array}$ \\
\hline
\end{tabular}


which especially facilitated the management of critically ill patients. While not widespread, new applications and functionalities were being developed and used. For example, physicians began to use electronic documentation but many did not believe that computerization saved time, although they appreciated its value for administrative functions and for producing printouts [28]. Networks of microcomputer workstations were used to write all inpatient orders linked to an EHR. While this significantly lowered patient charges and hospital costs, the systems required more physician time than did the paper charts [29]. Likewise, initial attempts at nurse charting failed because they required time-consuming manual data entry. Automated management of patient records became available through the development of patient data management systems which could be connected to bedside monitoring devices to record and interpret patient data in the EHR [30]. Some specific areas such as admitting, pharmacy, laboratory, surgery, radiology, respiratory therapy, and infectious diseases were either interfaced with or completely developed within EHRs [31]. However, laws still required hospitals and practitioners to be accountable for the accuracy and completeness of medical records and thus all documents had to be reviewed and signed. While regulatory and accrediting agencies restricted the auto-authentication of medical records, electronic signatures could and were being used within EHRs [32].

Soon, the use of EHRs produced massive amounts of health care data which were found to be valuable for epidemiologic review. However, secondary use of EHR data soon elucidated issues with the quality of these data for research and evaluation. Use of data for purposes other than those for which the data was collected showed that poor quality data often led to significant misinformation and potential patient harm [33].

\section{Clinical Decision Support}

It was recognized that medical information in EHRs could be used for CDS which generated a new major domain of medical informatics. Knowledge bases began to be designed as separate databases and used within EHRs.
Some academic EHRs included knowledge bases to feed CDS functions while few of the commercial systems did by $1992[12,34$, 35]. Early CDS included drug-allergy, drugdrug, and abnormal laboratory test results while other areas were being covered as well $[36,37]$. As an effort to influence physician decisions, CDS was built within Physician Order Entry (POE) [38] and required physicians to respond to computer-generated reminders to improve their compliance with preventive care protocols [39]. The benefit of sharing Medical Logic Modules (MLMs) was being tried in order to reduce efforts by avoiding that each group replicates what others had developed and evaluated. The Arden syntax [40] was an initial effort to show that CDS rules could be shared between different hospital EHRs with different databases and data dictionaries. Thus, in order to use data for CDS, numerous efforts to code data were emphasized and the use of "free-text" data was avoided whenever possible.

\section{The Need for Standards}

The increase of third party applications being used within EHRs required additional and specific interfaces to be developed. It soon became obvious that standards were needed. By 1992, Health Level Seven (HL7) [41] and IEEE P1157 [42] were being used as the main interface standards by homegrown EHRs and vendors to interface with other systems. The advantage of this approach was to reduce the ambiguity in data element definitions. As a number of EHRs and other applications began to be interfaced, the HL7 standard was refined and expanded into additional domains and became the most practical solution to aggregate ancillary systems like laboratory, microbiology, electrocardiogram, echocardiography, and other results into a central EHR [43]. The need for a consistent message format or syntax was recognized as only part of the problem. The need to use standardized dictionary codes (semantics) was spear headed by the National Library of Medicine and the development of the Universal Medical Language System (UMLS) reminding us today that computer systems come and go, but data last forever [44].
Data from medical devices such as ventilators, bedside monitors, and infusion pumps are critical for patient care. Manual entry of sporadic medical device data did not meet the needs of clinicians. The IEEE P1073 Medical Information Bus (MIB) standard developed to facilitate the interfacing with any type of medical device was only used by a small number of facilities due to the limited participation by medical device vendors [45]. However, Picture Archiving and Communication Systems (PACS) were being successfully used and found to improve the access, storage, and transfer of digital images [46].

\section{Data Exchange and Networks}

Data ownership and privacy became common issues whenever data storage and data exchange through computer networks were planned [19]. Despite these challenges, a number of community health information networks were in the developmental stages or at varying degrees of operability [47], and Singapore developed a national computer network for the medical and health community [48]. However, the technology raised several important ethical problems including data control and patient dignity along with other important ethical matters requiring solutions including data ownership, data liability, informed consent to use and retrieve, security, and access [49]. Other extensive views of EHR capabilities, functionalities, and use in 1992 can be found in The Computer-Based Patient Record: An Essential Technology for Health Care, Revised Edition [12] and in the paper by Reed Gardner on the past and future of clinical information systems in this anniversary edition of the Yearbook [50].

\section{EHR Use and Evolution by 2015}

Large health care organizations and government agencies are recognizing the value of information in EHRs to determine optimal patterns of care [51]. However, 
growing issues facing healthcare coverage, privacy, and especially the security of EHRs remain crucial obstacles for their acceptance. Patients, providers, and healthcare facilities continue to demand assurance that these records are securely protected $[52,53]$. Thus, as EHR use has increased over time, technical issues continued to be overshadowed by procedural, professional, social, political, and especially ethical issues and the need for compliance with standards and information security [54].

A 2004 random sample of healthcare facilities from across the U.S. found that $13 \%$ of respondents had an EHR system fully implemented while $10 \%$ did not have or did not plan to have an EHR system. The majority of respondents $(62 \%)$ used a vendor EHR system and most were not aware or slightly aware of the ASTM E1384 standards for the minimum data elements that should be included in all EHR systems [55]. Some healthcare facilities used a single EHR for nearly all care they provided while others used EHRs from more than one vendor or a homegrown EHR [56].

The number of academic institution developed EHRs in use have declined and been replaced by large vendor EHRs since 1992 [57]. However, the number of EHR-related articles published by academic institutions has significantly increased. From 1991-2005, most articles were published in English and were from North America, followed by the UK, Switzerland, the Netherlands, and Norway [58]. Since 2005, EHR innovation and development and published articles have steadily increased from most European countries, Australia, and Asia, including the establishment of an IMIA journal solely dedicated to applied clinical informatics $[59,60]$.

Most EHRs are now web/client-server-based, use relational databases, data access and entry screens are navigated using mouselike scrolling and pointer devices. In the U.S., the increase in EHR adoption was stimulated by the 2009 stimulus plan's Meaningful Use initiative. Electronically sharing medical information from one facility to another has become more frequent and many medical organizations have implemented EHRs and health information exchange (HIE) networks [61]. The Veterans Administration in the U.S. Health Exchange has advanced HIE interoperability standards and patient consent policies [62]. In an effort to reach the same goal, the Canada Health Infoway initiative helped develop interoperable EHRs nationwide [63]. Australia launched a personally controlled EHR designed around the needs of consumers [64]. Estonia implemented a nationwide electronic health record system which gives full access to its citizens [65]. EHRs are implemented and used in ambulatory care in sub-Saharan Africa [66]; and Hong Kong's web-based electronic patient record system allows integrated, real time patient-based information to be shared in clinics, and private and public hospitals [67]. To exchange a common set of data elements, a common terminology such as SNOMED and LOINC, common data structures, and a common transport standard, the HL7 Clinical Document Architecture (CDA) and The American Society for Testing and Materials (ASTM International) Continuity of Care Record (CCR) are being used [68]. Today, the ASTM CCR is usually viewed within an HL7 message. Remote follow-up of implanted medical devices can be made through data exchanged via an HL7/XML communication protocol to a patient's clinical information stored in the local EHR $[69,70]$.

\section{New Functionality and Use}

EHR records are now being created, used, edited, and viewed by multiple independent entities including primary care physicians, hospitals, insurance companies, and patients. EHRs are increasingly being used in primary-care exam rooms to document and access patients' records along with online medical information and decision-making tools, and prescribe medications. They have changed the dynamics of the patient-clinician interaction through clinician-patient email, virtual consults, and telemedicine [71-75].

Additional parts of the paper chart continue to be incorporated into the EHR since 1992. Digital pathology includes the information technology that allows for the management of data and images [76, 77]. Likewise, results from laboratories that are external to the health care enterprise are being integrated into the EHR [78]. Providers are now using order sets, voice recognition, barcodes, and documentation templates to directly enter information into the EHR and decision support rules along with computerized provider order entry (CPOE) are used daily [79, 81]. Mobile devices with high-resolution cameras are also used by clinicians to capture images from the bedside and insert them into the EHR [82]. Medication ordering is now coupled with CDS and includes e-prescribing interfaces to local pharmacies [83]. The inclusion of mental and behavioral health data in the EHR has significantly improved the quality of medical care and increased the use of medical services among patients $[84,85]$. However, there is mounting pressure to decrease or remove the need for a patient's consent to access their medical information. Mental health information is sensitive and potentially damaging if privacy is breached and can result in patients being reluctant to seek treatment if they cannot be assured of confidentiality [86]. Access to behavioral health data becomes even more complicated due to variations in states, countries, and international laws.

While more information is being stored in EHRs and shared with multiple facilities, EHRs are now also being used in nursing homes. This additional environment has been a challenge due to the multiplicity of different providers in a home, the physical structure of the facilities, multiple facility organizations, and high costs of implementation and maintenance. However, EHRs in nursing homes have improved communication between providers, consultants, hospital, and nursing home staff [87], and nursing homes are increasingly introducing EHRs into nursing practice [88]. Also, EHRs are being used by home health or hospice care [89], organizations that provide care to the homeless population [90], and departments of corrections [91].

The increased demand by patients to access their healthcare data has led to more personal use of the EHR [92]. Personal Health Records (PHRs) are now interfaced with applications within EHRs and are used by most large facilities and vendors [93]. Many patients are taking a more active role in managing their medical data which is essential for patient-centered care [94]. Patient-centered-care allows patients to add personal stories of key life events both medical and non-medical that enable clini- 
cians to better understand what matters and is important to patients, and what are their personal health goals and care preferences $[95,96]$. Recent reports have highlighted the need for efforts to better understand the collection and use of this information in the EHR [97] and there is a lack of consensus on how PHR success will be determined [98, 99]. There are no comprehensive laws or procedures regarding patients' access rights to EHRs [100]. Another problem may be that the use of PHRs may be challenging for some older adults or those of lower socioeconomic status and with low health literacy [101].

Family health histories are also being entered into EHRs. They are used to assess disease risk and offer insight into the interplay between inherited and social factors relevant to patient care [102]. Additionally, the human genome has now been decoded and whole-exome and whole-genome sequencing results are now being stored in the EHR [103, 104]. DNA results can be provided to the practitioner, used for CDS, and collected data in the EHR serve as a source of phenotypic information for analytic purposes [105]. Together, these data sources make the EHR the paramount source of phenotypic information and genomic research [106]. However, there remain challenges in extracting phenotypic data that sometimes need to be inferred from multiple sources. But, recent work has made progress in translating "omic" data into patient care and CDS using pharmacogenomics data $[107,108]$. Biobanks are now linked to personal and family health information in EHRs to accurately identify subjects with specific diseases and phenotypes and to identify genotype-phenotype associations [109].

In addition to patient and family health benefits, public health has found increased value in EHRs. Biosurveillance systems are linked to EHRs to detect events of public health significance [110]. Adapting EHR systems to serve public health needs provides the possibility of enormous advances in public health practice and policy [111]. Distributed networks for public health surveillance allow public health to initiate custom queries against participating EHRs while the data remain behind each practice's firewall [112].

CDS applications continue to be promoted as one of the key features of EHRs. Diagnostic decision support systems were some of the earliest examples of medical informatics innovations. Computer-based diagnostic systems are available commercially and studies have shown that these computer programs have strengths and limitations [113, 114]. In addition, a comprehensive taxonomy of front-end CDS tools has been developed and validated. A subsequent survey of commercial EHR vendors and leading healthcare institutions revealed a small core set of common CDS tools, but identified significant variability in the remainder of CDS content [115].

Modern patient care depends on a number of different medical devices in order to monitor a patient's vital signs, infuse medications, and maintain life support. Data from medical devices such as ventilators, infusion pumps, bedside and portable monitors, and others are interfaced to EHRs through custom interface applications [116, 117]. Not only is this data valuable for a patient's EHR, but it is essential for CDS applications to help prevent patient harm. Integrated Development Environments are now used along with new programming languages to facilitate and accelerate the development of CDS and other applications. A comprehensive discussion of current CDS capabilities can be found in Greenes's "Clinical Decision Support" [118].

The increased amount of patient information stored in the EHR continues to include a large variety of free-text documents. This spawned the need for the use of Natural Language Processing (NLP) to read and code free-text data which has become common within most EHRs [119-121]. NLP and inference rules have acceptable performance for understanding and finding previously hidden information in dictated documents and especially for adding problems to the problem list [122].

The growing amount and availability of EHR data also present new opportunities for discovering new knowledge about diseases. In the past decade, there has been an increase in big- data and text mining focused on the identification of disease associations [123]. Big-data offers the promise of large-scale EHR data analysis of outcomes, patterns, temporal trends, and correlations. Many think the evolution of Big Data analytics will use EHR data and move us from description and reporting diseases to forecasting, predictive modeling, and decision optimization [124].

However, EHRs are often considered as incomplete. In 2011, fewer than 5\% of anesthesia departments used an EMR that was anesthesia specific $[125,126]$, primary care functions frequently remained unsupported [127], and pediatricians reported the absence of pediatric data and functions in EHRs [128-130]. Not all available patient information is entered due to physicians' and other providers' complaints about increased workload and the inflexibility of EHRs and CPOE [131]. These complaints spawned the use of medical scribes, who are trained medical information managers specialized in charting physician encounters in real-time and assisting in the navigation of the EHR [132]. Implementation also continues to be limited in rural areas due to financial barriers [133]. Open source technology is becoming a solution to overcome the problems of high-cost and inflexibility associated with the proprietary EHRs. Open source EHRs are being used in a number of countries across the world and mainly in Sub-Saharan Africa and South America [134-137]. While open source EHRs may have limited capabilities currently, they offer a better option than paper and continue to improve their capabilities, functionalities, and user acceptance [138].

Still, healthcare providers are under increasing pressure to enable widespread access to their EHRs for the patients they serve. The meaningful use incentive program in the U.S. has been a significant driver encouraging this access. Elsewhere, the cloud has become extremely efficient and successful at establishing digital identities for individuals and making EHRs interoperable across heterogeneous systems. As the healthcare industry contemplates providing patients more access to their EHRs, the solution could leverage existing cloud technology $[139,140]$.

EHR data generated in the care of patients are also widely used to support clinical research and quality improvement [141]. The enormous amount of data being collected by EHRs has generated additional value when integrated and stored in enterprise data warehouses (EDWs). The EDW allows all data from organizations with numerous inpatient 
and outpatient facilities to be integrated and analyzed [142]. These data are not only an essential tool for management and strategic decision making, but also for enhanced data exploration, cohort identification, population management, and patient specific CDS. Patient data that was previously stored on removable disk packs or tape are now stored online; birth to death.

\section{Implementation and Value}

As stated, this paper focuses on the overall state and use of EHRs in 1992 and their evolution as of 2015. Some of the functionality and use described resulted in common use and opened new domains for most EHRs that have become standard while others may have only been reported in a single paper and later found to have little value or were never implemented outside the original facility. Perceived value and use are often dependent on the workflow of a medical specialty or facility. Thus, published work describing EHR capabilities was included, although it was beyond the scope of this paper, to comment directly on value or sustainability for each case. Further, an unsuccessful initial development may be used to identify new and useful functionality for future improvement.

\section{Addressing Hurdles to Optimal Use of the EHR}

Some healthcare professionals continue to develop workarounds and rely on paper alternatives rather than using EHRs [143]. Understanding of the reasons why EHR functionalities vary and why there is a need for workarounds remains important to facilitate user-centered design and create needed education for EHR use [144, 145]. There also continues to be discussion on the right balance between information overload and the right-and helpful-information [146] including the need for restrictions on the use of copy and paste to limit the growing challenge of 'note bloat' [147]. Moreover, many studies have demonstrated unintended negative consequences of the use of EHRs on the quality of care [148-151]. Research on the application of human factors to the design and development of EHRs has been used to improve their use and prevent unintentional consequences [152]. A centralized, nonpartisan board with an appropriate legal and regulatory infrastructure to ensure the safety of EHRs has been proposed to facilitate the identification of EHR-related adverse events and errors and potentially create a safer and more effective health care delivery system [153].

With the advanced capabilities of EHRs, the enormous amount of information that may not always be easy to locate and the potential of unintended consequences, education and training have become major issues. Clinicians are now being prepared to practice in an EHR-mediated world including electronic medical education [154-156]. Some medical schools are including lectures on EHR use. Educational systems have been integrated into the EHR [157]. Students of health professions and practicing professionals can access and interact with a set of representative solutions using an interdisciplinary EHR educational portal [158]. Likewise, medical simulation centers have been integrated into EHRs which provide realistic environments for usability testing, training, and evaluation of human-computer interactions [159]. A major role of simulation training is also to test the efficacy and safety of EHR-user interfaces, identify implementation gaps, and improve their safety [160-162].

Many medical school curricula have also added content on information retrieval [163]. Linking the EHR to the digital library and thus allowing the automatic integration of clinical data with relevant knowledge-based information to support informed decisions has been an important informatics goal [164]. Online information resources are now linked to EHRs and the role of medical librarians has changed to support this effort [165]. Infobuttons are forms of CDS and education tools that use information about the clinical context (institution, user, patient) in which an information need arises to provide direct access to relevant information from knowledge resources that accept context parameters from an EHR. Using the knowledge base of resources and information needs, these tools generate a set of links that direct the user to relevant information
[166]. Infobuttons are standards-based, open source Web services that disseminate specific information in multiple EHR systems anticipating clinicians' questions and providing automated links to relevant information in knowledge resources [167]. Additional history and information of EHR capabilities and functionality can be found in the chapter "Electronic Health Record Systems" in "Biomedical Informatics: Computer Applications in Health Care and Biomedicine" [168].

\section{Discussion}

\section{Expectations for and Realization of EHRs in 1992}

The changes in the use and handling of EHR information initiated by new technology, especially the microcomputer and internet would have been hard to predict prior to 1992. New technologies and events have had and will continue to have a profound effect on the development and use of future EHRs (Table 2). Even prior to the 1990s, it was expected that EHRs would become technically and economically feasible on a broad scale [169] and their data would be transmitted across high speed digital networks in response to user and patient needs [170]. Those are common daily occurrences in many places around the world and modern medical care is dependent on this ability. The Institute of Medicine's 1991 recommendations stated that by the year 2000, each physician's office should use an EHR in order to improve patient care and its provided rules and regulations focused on patient privacy and confidentially have only been partially realized as of 2015 [12]. Likewise, while EHR data in form of text, images, and voice are available instantaneously via the internet from virtually anywhere in the world, providers still do not have all the patient information they need $[171,172]$. However, it is hard to downplay the enormous advancements that have taken place. Meaningful Use in the U.S. has had a positive influence on the implementation of EHRs in more hospitals and primary care physician offices [173]. While, some feel 
It had been expected that EHRs would eliminate data duplication [179] and save time by automatically issuing routine reports, improve clinical practice, simplify quality assurance, ease data collection, generate reports, treatment plans, and medication orders without removing records from circulation [180]. While we see some of these expectations realized today, we still suffer from data duplication and many clinicians do not believe EHRs are saving time.

Finally, we expected that health care reform and the changing healthcare environment would require medical data to be in electronic form that could be accessed by providers, hospitals, government organizations, and private health care management. Thus, the "successful" medical practitioners in the future would need to change the way in which they provide care and would be those whose practices have "life-long" EHRs that allow comprehensive medical record keeping, inclusive of patient charting, billing, coding, scheduling, and data reporting to third parties [181-183]. We have seen that the healthcare reform and the changing environment worldwide have definitely accelerated the implementation and use of EHRs. However, how we measure success was not defined back in 1992. A number of events and technologies helped to accelerate the development of EHRs. Unfortunately, there also has been a number that disrupted or derailed that effort (Table 3). ces have been made, computer diagn failed to reach the initial expectations of 1992.

The expectation to have EHRs used in the ambulatory setting has been realized and EHRs have been interfaced to or combined with hospital EHRs [177]. The use of EHRs in the ambulatory setting has been associated with increased adherence to recommended care [178]. This has been accomplished in part by the expected use of portable computing devices that can access patient information and allow patient information to be charted in the busy medical office [21, 22].

The expectation that EHRs would only complement and not replace the traditional office record, unfortunately, continues to be reality in many facilities around the world [18]. However, the expectation had implied that the EHR could be implemented in a modular step-by-step fashion rather than all at once with its high associated costs.

\section{Where Are EHRs Expected to Be in the Next 25 years?}

Current EHRs do not meet the needs of today's distributed systems and of the rapidly changing healthcare environment $[184,185]$. The ability of applications to communicate, interpret, and act intelligently upon complex healthcare information has assumed paramount importance [186]. The future lies in the development of flexible component-based architectures that can operate seamlessly within the workflow of a healthcare environment (Table 4). Much of EHR adoption continues in an environment shaped by paper chart thinking, which continues to limit successs [187]. Further research is needed to understand 
Table 3 Events and technologies that helped to accelerate and disrupt or derailed planned development of EHRs

\begin{tabular}{|l|l|}
\hline Accelerate & Disrupt or Derailed \\
\hline Personal computers & Data quality issues \\
Internet-cloud & Lack of certain standards \\
Email, pagers/cell phones & Poor user design \\
Local and wide area networks & Alert fatigue \\
Client-server technology & IEEE P1073 Medical Information Bus (MIB) standard not used by medical \\
& device vendors \\
Natural Language Processing & Lack of vendor Interoperability (APIs) \\
Human genome & Social and political factors \\
Interface standards & Lack of data security technology \\
Email, pagers and smart phones & Innovation barriers \\
Open-source & Financial/business goals trump medical needs: Billing vs patient care \\
Wifi & Clinician's inability to completely describe the clinical story of the patient \\
& within EHRs \\
Picture Archiving \& Communication Systems & Clinician need to fit medicine into a limited array of codes \\
Personal Health Records & Lack of understanding of how to store and report genetic information \\
Family history information & Limited use of open-source EHRs \\
SNOMED-LOINC & Inflexible, proprietary, nonintuitive, expensive, difficult to maintain and \\
& rarely interoperable EHRs \\
Unified Medical Language System & Unintended consequences \\
BAR codes & Differences in semantics and data dictionaries \\
Meaningful Use in the U.S. & Lack of clinician input and testing in application design and development. \\
Improved relational databases & Billing and regulatory compliance driving clinical documentation \\
Reduced cost of data storage and hardware & \\
Integrated Development Environments & \\
Increased number of EMR vendors & \\
\hline
\end{tabular}

human-technology integration factors that may be causing clinicians to continue to rely on paper alternatives to the EHR [143]. More research is needed to determine how to integrate the EHR into patient encounters more effectively [188] and provide clinicians with a greater control of the EHR resulting in greater flexibility to fit to their needs and preferences [189]. Many physicians are optimistic about the future benefits of EHRs, but are frustrated with the non-intuitive and multi-click interfaces and cumbersome data searches of existing EHRs [190].

While the goal of creating integrated EHRs is within our reach, its success will depend chiefly on the creation and especially adoption of standards by all international parties [191]. HIE which will enable data integration, semantic interoperability, and CDS across multiple EHRs has been a desired but largely unattained aim of clinical informatics, especially in commercial EHR systems [192, 193]. The opportunity for enabling such scalable CDS will require vendor-supported, web-based CDS development platforms along with vendor-supported application programming interfaces (APIs) allowing the use of innovative, pluggable, interchangeable, and API-based CDS applications. This will probably require initially using custom EHR APIs and then moving towards standardized EHR APIs which are already starting to be supported by major commercial EHR vendors [194]. Web applications that run on the Substitutable Medical Apps, Reusable Technologies (SMART) platform are starting to be used. The SMART platform is an example of an emerging framework that enables EHR systems to behave as "iPhone like platforms" by exhibiting an API for easy addition and deletion of third party applications [195].

Genetic testing has had limited impact on routine clinical care. Widespread adoption of future EHRs will provide the needed methods of disseminating genetic testing into diverse care settings [196]. However, the successful integration of genomic data will require significant redesign of existing EHRs. The future EHRs will be able to manage the size and complexity of genetic test results, use standards for combining clinical and genetic data, and eliminate the current limitations in the capacity to store and analyze genetic data. Related challenges of the uncertainty in the interpretation of results and privacy concerns specific to genetic testing will be resolved and EHRs will provide the genetic, environmental, and lifestyle data needed for precision medicine and the improvement of patient care [197].

The capabilities of NLP will continue to advance and its use will be needed to code the increasing dictated free-text produced by the concomitant advances and use of voice recognition. Data storage capabilities to handle the massive amount of patient information will increase as storage capacities will increase and the related costs decrease. Transforming clinical data into knowledge to improve patient care has been the goal of biomedical informatics professionals [198]. With the increase in the amount of electronic healthcare data, the potential for knowledge discovery will be substantial if data are managed in innovative and effective ways [199]. Some data sets will be so large or complex that traditional data processing applications will be inadequate. This will require the creation of new big data applications especially for data sharing. Analyses of this "big data" will provide the next step to transform healthcare data into actionable knowledge.

Displaying large amounts of irrelevant patient information can lead to information overload and user error. Next-generation interfaces for EHRs will use CDS to synthesize fragments of evidence documented throughout the entire record to understand the etiology of a disease and of its clinical manifestation in individual patients. Context-based EHRs will employ biomedical ontologies and disease models as sources of domain knowledge to identify relevant parts of the record to display [200]. Usability, the ultimate goal of recording and managing patient data, will require improved technical considerations in addition to appropriate methodologies for medical data management [201]. Since EHRs will continue to have the potential to increase medical errors, built-in EHR applications that detect physician-level 
usage of EHR features, and clinical simulations will be needed to analyze human-computer interaction in real healthcare settings $[162,202]$. As EHRs continue to change and improve, engineering and reengineering will still be needed in order to increase their beneficial potential while at the same time improve their safety.

The fundamental role and purpose of the EHR in the future will be a data repository based on international standard APIs for the retrieval and storage of data. It will be coupled with facility and vendor provided, and user selected applications for data review and entry and especially CDS. In addition to health data, social, economic, behavioral, and environmental data will play a vital role in providing and especially improving healthcare. The applications will be interchangeable, not dependent on EHR versions and updates, and will facilitate innovation like the current Smart Phone applications [203].

EHR safety concerns involving both unsafe technology and unsafe use will persist in the future. Mounting pressure will require EHR implementations to build a robust infrastructure to monitor and learn from adverse events, errors, and potential adverse events and errors [204]. These errors will

\section{Table 4 Design and capabilities of EHRs in the next 25 years}

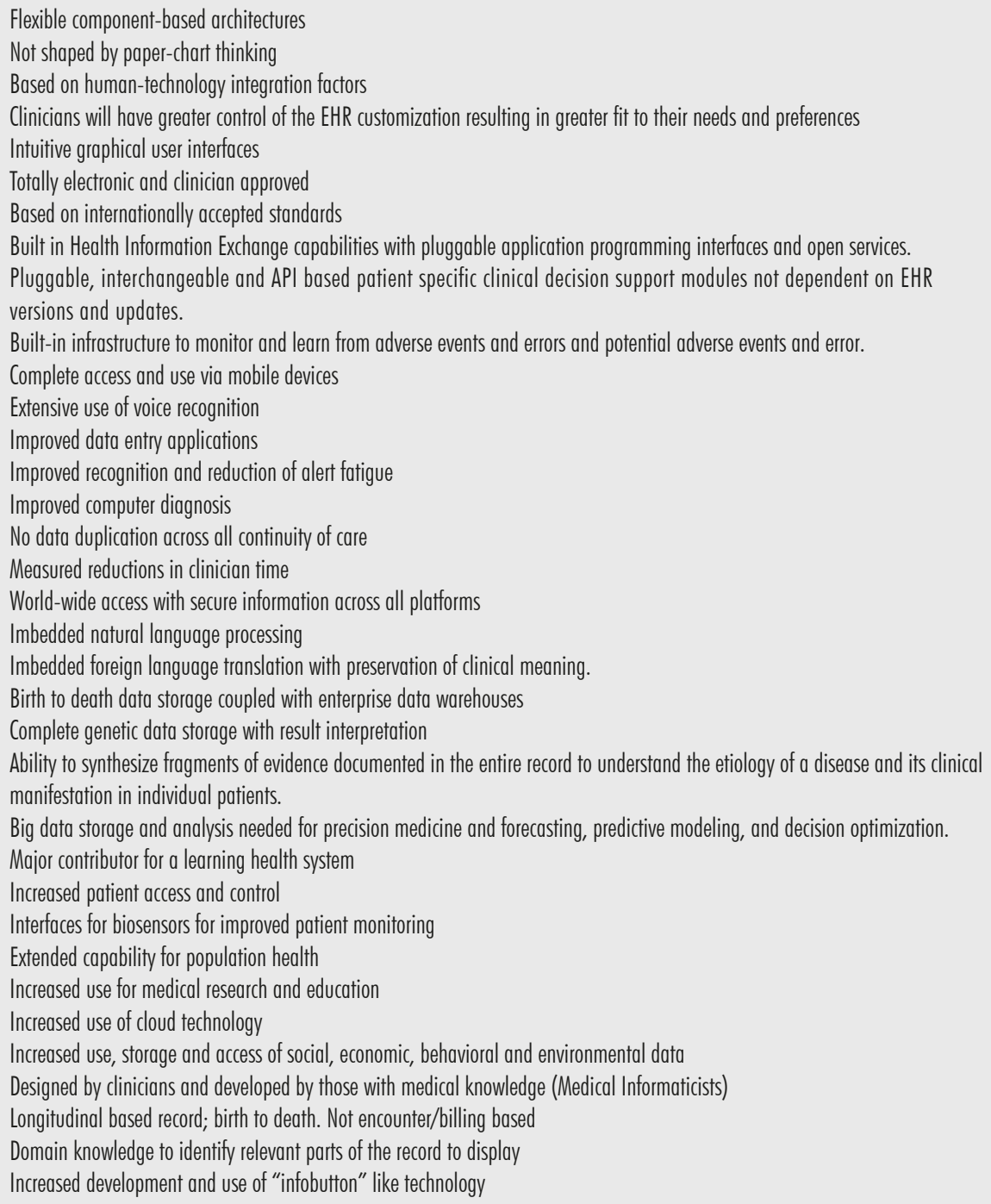

be electronically and securely reported to a centralized, nonpartisan body (like a patient safety organization) whose purpose will be to find ways for future prevention rather than punishment [153].

Tourism as well as international business travel creates health risks for individuals and populations [205]. International HIE standards like those proposed by the International Medical Informatics Association will provide travelers with their complete personal medical information interfaced with their primary EHR [206]. This information will be available on mobile phones and other future mobile devices. Applications will allow that information to be securely uploaded to any standards-based EHR using state of the art cloud-like technologies to provide current medical care. New information, including patient entered, will be stored in the primary EHR [207, 208]. This will be coupled with tele-health which will allow the patients' primary care physicians to directly see and communicate with other healthcare providers in urban as well as rural areas worldwide through computerized language translation and the preservation of clinical meaning [209]. Thus, it will be necessary to develop specifications for privacy and trust agreements between international partners [210, 211].

Use of mobile devices with high-resolution cameras by clinicians to capture images from the bedside and incorporate them into the EHR will increase. However, secure and efficient ways to manage and share digital images are lacking to date. Future clinical image applications should more closely link clinical images and documentation and should consider enabling secure transmission over public WiFi or cellular networks. The capability to share data and harness their potential to generate knowledge rapidly and inform decisions will have transformative effects improving health. The infrastructure to achieve this goal at scale --marrying technology, process, and policy-- is commonly referred to as the Learning Health System [212]. We have been extremely fortunate to have the foresight and perseverance of a number of early biomedical informatics pioneers. While, we hope for a totally electronic and clinician accepted EHR within the next 25 years, we'll have to wait and see. 
However, based on the current growth in education and training of numerous talented and innovative people, the future looks bright.

\section{Acknowledgments}

I'd like to thank Kyle V. Johnson, Stephen Howe, James F. Lloyd and Jacob S. Tripp for input on classifying events that have either accelerated or disrupted/derailed EHR development.

\section{References}

1. Weed LL. The problem oriented record as a basic tool in medical education, patient care and clinical research. Ann Clin Res 1971 Jun;3(3):131-4.

2. McDonald CJ, Murray R, Jeris D, Bhargava B, Seeger J, Blevins L. A computer-based record and clinical monitoring system for ambulatory care. Am J Public Health 1977 Mar;67(3):240-5.

3. Pryor TA, Gardner RM, Clayton PD, Warner HR. The HELP system. J Med Syst 1983 Apr;7(2):87-102.

4. Stead WW, Hammond WE, Straube MJ. A chartless record--is it adequate? J Med Syst 1983 Apr;7(2):103-9.

5. Clayton PD, Anderson RK, Hill C, McCormack M. An initial assessment of the cost and utilization of the Integrated Academic Information System (IAIMS) at Columbia Presbyterian Medical Center. Proc Annu Symp Comput Appl Med Care 1991:109-13.

6. Davis LS, Collen MF, Rubin L, Van Brunt EE. Computer-stored medical record. Comput Biomed Res 1968 May;1(5):452-69.

7. Blum BI. Understanding computer basics. MD Comput 1984;1(1):59-65.

8. Barnett GO. The application of computer-based medical-record systems in ambulatory practice. New Engl J M 1984 Jun 21;310(25):1643-50.

9. Walker HK. Grady Memorial's integrated database improves speed, accuracy and cost containment. Comput Healthc 1989 Mar;10(3):36-7, 40, 2.

10. Ornstein SM, Garr DR, Jenkins RG. A comprehensive microcomputer-based medical records system with sophisticated preventive services features for the family physician. The J Am Board Fam Pract 1993 Jan-Feb;6(1):55-60.

11. Kuperman GJ, Maack BB, Bauer K, Gardner RM. Innovations and research review: the impact of the HELP computer system on the LDS Hospital paper medical record. Top Health Rec Manage 1991 Nov;12(2):76-85

12. Institute of Medicine. The Computer-based Patient Record: An Essential Technology for Health Care. Revised Edition. Dick RS, Steen EB, Detmer DE, editors. Washington, DC: National Academy Press; 1997.

13. Barnett GO. Computer-stored ambulatory record (COSTAR) U.S. Dept. of Health, Education, and Welfare, Public Health Service, Health Resources Administration, National Center for Health Ser- vices Research in [Rockville, Md.]; 1976. 40 p.

14. Schultz JR, Cantrill SV, Morgan KG. An Initial Operational Problem Oriented Medical Record System-For Storage, Manipulation and Retrieval of Medical Data. AFIPS-Conference Proceedings. 1971;38.

15. Stead WW, Hammond WE. Computer-based medical records: the centerpiece of TMR. MD Comput 1988 Sep-Oct;5(5):48-62.

16. McDonald CJ, Tierney WM. The Medical Gopher--a microcomputer system to help find, organize and decide about patient data. Western J Med 1986 Dec;145(6):823-9.

17. Ornstein SM, Oates RB, Fox GN. The computer-based medical record: current status. J Fam Pract 1992 Nov;35(5):556-65.

18. Rodnick JE. Should the complete medical record be computerized in family practice? An opposing view. J Fam Pract 1990 Apr;30(4):460-4.

19. Regan BG. Computerised information exchange in health care. Med J Aust 1991 Jan 21;154(2):140-4.

20. Salenius SA, Margolese-Malin L, Tepper JE, Rosenman J, Varia M, Hodge L. An electronic medical record system with direct data-entry and research capabilities. Int J Radiat Oncol, Biol, Phys 1992;24(2):369-76.

21. Wormuth DW. SCUT: clinical data organization for physicians using pen computers. Proc Annu Symp Comput Appl Med Care 1992:845-6.

22. Specthrie L, Berg W, Fishman S, Walker L, Gapay L. Power to the portables. Healthc Inform 1992 Aug;9(8):22-30.

23. American Health Information Management Association. Position statement. Issue: Healthcare reform. J AHIMA 1992 Nov;63(11):suppl 2 p.

24. Widman LE, Freeman GL. A-to-D conversion from paper records with a desktop scanner and a microcomputer. Comput Biomed Res 1989 Aug;22(4):393-404.

25. Massengill SP. Image-based document management systems for medical records. Top Health Rec Manage 1992 Mar;12(3):40-8.

26. Litt HI, Loonsk JW. Digital patient records and the medical desktop: an integrated physician workstation for medical informatics training. Proc Annu Symp Comput Appl Med Care 1992:555-9.

27. Higgins SB, Jiang K, Swindell BB, Bernard GR A graphical ICU workstation. Proc Annu Symp Comput Appl Med Care 1991:783-7.

28. Kainz C, Lassmann R, Schaffer H, Hanzal E, Deutinger J. Survey of computerized obstetric information systems in Austria. Arch Gynecol Obstet 1992;252(2):87-91.

29. Tierney WM, Miller ME, Overhage JM, McDonald CJ. Physician inpatient order writing on microcomputer workstations. Effects on resource utilization. JAMA 1993 Jan 20;269(3):379-83.

30. Brennan P. Winning the paper chase. Bedside terminals help clear the record. Health Prog 1989 Oct;70(8):66-8.

31. Burke JP, Classen DC, Pestotnik SL, Evans RS, Stevens LE. The HELP system and its application to infection control. J Hops Infect 1991 Jun;18 Suppl A:424-31

32. Kadzielski MA, Reynolds MB. Legal review: auto-authentication of medical records raises verification concerns. Top Healh Inf Manage 1993 Aug;14(1):77-82.
33. Hierholzer WJ, Jr. Of guides and guidelines. Infect Control Hosp Epidemiol 1992 Jun;13(6):329-30.

34. Shortliffe EH. Computer programs to support clinical decision making. JAMA $1987 \mathrm{Jul}$ 3;258(1):61-6

35. Warner HR, Olmsted CM, Rutherford BD. HELP-a program for medical decision-making. Comput Biomed Res 1972 Feb;5(1):65-74.

36. Johnston ME, Langton KB, Haynes RB, Mathieu A. Effects of computer-based clinical decision support systems on clinician performance and patient outcome. A critical appraisal of research. Ann Intern Med 1994 Jan 15;120(2):135-42.

37. Evans RS, Larsen RA, Burke JP, Gardner RM, Meier FA, Jacobson JA, et al. Computer surveillance of hospital-acquired infections and antibiotic use. JAMA 1986 Aug 22-29;256(8):1007-11.

38. McDonald CJ. Protocol-based computer reminders, the quality of care and the non-perfectability of man. New Engl J Med 1976 Dec 9;295(24):1351-5.

39. Litzelman DK, Dittus RS, Miller ME, Tierney WM. Requiring physicians to respond to computerized reminders improves their compliance with preventive care protocols. J Gen Intern Med 1993 Jun;8(6):311-7.

40. Hripcsak G. Arden Syntax for Medical Logic Modules. MD Comput 1991 Mar-Apr;8(2):76, 8.

41. Hammond WE. Health Level 7: an application standard for electronic medical data exchange. Top Health Rec Manage 1991 Jun;11(4):59-66.

42. Harrington JJ. IEEE (Institute of Electrical and Electronic Engineers) P1157 Medical Data Interchange (MEDIX): application of open systems to health care communications. Top Health Rec Manage 1991 Jun;11(4):45-58.

43. Cahill BP, Holmen JR, Bartleson PL. Mayo Foundation Electronic Results Inquiry, the HL7 connection. Proc Annu Symp Comput Appl Med Care 1991:516-20.

44. McDonald CJ, Martin DK, Overhage JM. Standards for the electronic transfer of clinical data: progress and promises. Top Healh Rec Manage 1991 Jun;11(4):1-16.

45. Shabot MM. Standardized acquisition of bedside data: the IEEE P1073 medical information bus. Int J Clin Monit Comput 1989 Dec;6(4):197-204.

46. Lemke HU. Communication networks for medical image transmission. Strahlenther Onkol 1993 Sep;169(9):512-20.

47. Brunner BK. Health care-oriented telecommunications: the wave of the future. Top Healh Inf Manage 1993 Aug;14(1):54-61.

48. Lim P. MediNet: Singapore's nationwide medical network. Ann Acad Med Singapore 1990 Sep;19(5):656-61.

49. Kluge EH. Advanced patient records: some ethical and legal considerations touching medical information space. Methods Inf Med 1993 Apr;32(2):95-103.

50. Gardner RM. Clinical Informaiton Systems: Looking Back and Looking Forward. Yearb Med Inform 2016.Zitat einfügen

51. Dolin RH. Outcome analysis: considerations for an electronic health record. MD Comput 1997 Jan-Feb;14(1):50-6.

52. Almulhem A. Threat modeling for electronic health record systems. J Med Syst 2012 Oct;36(5):2921-6. 
53. Ruland CM, Brynhi H, Andersen R, Bryhni T. Developing a shared electronic health record for patients and clinicians. Stud Health Technol Inform 2008;136:57-62.

54. Gaunt N, Roger-France F. Security of the electronic health care record--professional and ethical implications. Stud Health Technol Inform 1996;27:10-22.

55. Watzlaf VJ, Zeng X, Jarymowycz C, Firouzan PA. Standards for the content of the electronic health record. Perspect Health Inf Manag 2004;1:1.

56. Payne T, Fellner J, Dugowson C, Liebovitz D, Fletcher G. Use of more than one electronic medical record system within a single health care organization. Appl Clin Inform 2012;3(4):462-74.

57. Koppel R, Lehmann CU. Implications of an emerging EHR monoculture for hospitals and healthcare systems. J Am Med Inform Assoc 2015 Mar;22(2):465-71.

58. Wen HC, Ho YS, Jian WS, Li HC, Hsu YH. Scientific production of electronic health record research, 1991-2005. Comput Methods Prograns Biomed 2007 May;86(2):191-6.

59. Kim GR, Lehmann CU. In search of dialogue and discourse in applied clinical informatics. Appl Clin Inform 2009;0(1):1-7.

60. Lehmann CU, Altuwaijri MM, Li YC, Ball MJ, Haux R. Translational research in medical informatics or from theory to practice. A call for an applied informatics journal. Methods Inf Med 2008;47(1):1-3.

61. Ben-Assuli O, Shabtai I, Leshno M. Using electronic health record systems to optimize admission decisions: The Creatinine case study. Health Informatics J 2015 Mar;21(1):73-88.

62. Byrne CM, Mercincavage LM, Bouhaddou O, Bennett JR, Pan EC, Botts NE, et al. The Department of Veterans Affairs'(VA) implementation of the Virtual Lifetime Electronic Record (VLER): findings and lessons learned from Health Information Exchange at 12 sites. Int J Med Inform 2014 Aug;83(8):537-47.

63. Giokas D. Canada Health Infoway - Towards a National Interoperable Electronic Health Record (EHR) Solution. Stud Health Technol Inform 2005;115:108-40.

64. Pearce C, Bainbridge M. A personally controlled electronic health record for Australia. J Am Med Inform Assoc 2014 Jul-Aug;21(4):707-13.

65. Tiik M, Ross P. Patient opportunities in the Estonian Electronic Health Record System. Stud Health Technol Inform 2010;156:171-7.

66. Tierney WM, Rotich JK, Smith FE, Bii J, Einterz RM, Hannan TJ. Crossing the "digital divide:" implementing an electronic medical record system in a rural Kenyan health center to support clinical care and research. Proc AMIA Symp 2002:792-5.

67. Sek AC, Cheung NT, Choy KM, Wong WN, Tong AY, Fung VH, et al. A territory-wide electronic health record--from concept to practicality: the Hong Kong experience. Stud Health Technol Inform 2007;129(Pt 1):293-6.

68. Ferranti JM, Musser RC, Kawamoto K, Hammond WE. The clinical document architecture and the continuity of care record: a critical analysis. J Am Med Inform Assoc 2006 May-Jun;13(3):245-52.

69. van der Velde ET, Foeken H, Witteman TA, van Erven L, Schalij MJ. Integration of data from remote monitoring systems and programmers into the hospital electronic health record system based on international standards. Neth Heath J 2012 Feb;20(2):66-70

70. Rinner C, Janzek-Hawlat S, Sibinovic S, Duftschmid $\mathrm{G}$. Semantic validation of standard-based electronic health record documents with W3C XML schema. Methods Inf Med 2010;49(3):27180.

71. Asan O, Young HN, Chewning B, Montague E. How physician electronic health record screen sharing affects patient and doctor non-verbal communication in primary care. Patient Educ Couns 2015 Mar;98(3):310-6.

72. Doyle RJ, Wang N, Anthony D, Borkan J, Shield RR, Goldman RE. Computers in the examination room and the electronic health record: physicians' perceived impact on clinical encounters before and after full installation and implementation. Fam Pract 2012 Oct;29(5):601-8.

73. Abramson EL, BarronY, Quaresimo J, Kaushal R. Electronic prescribing within an electronic health record reduces ambulatory prescribing errors. J Qual Patient Saf 2011 Oct;37(10):470-8.

74. Amadi-Obi A, Gilligan P, Owens N, O'Donnell C. Telemedicine in pre-hospital care: a review of telemedicine applications in the pre-hospital environment. Inf J Emerg Med 2014;7:29.

75. Ndlovu K, Littman-Quinn R, Park E, Dikai Z, Kovarik CL. Scaling up a Mobile Telemedicine Solution in Botswana: Keys to Sustainability. Front Public Health 2014;2:275.

76. Rojo MG, Castro AM, Goncalves L. COST Action "EuroTelepath": digital pathology integration in electronic health record, including primary care centres. Diagn Pathol 2011;6 Suppl 1:S6.

77. Wilkerson ML, Henricks WH, Castellani WJ, Whitsitt MS, Sinard JH. Management of laboratory data and information exchange in the electronic health record. Arch Pathol Lab Med 2015 Mar;139(3):319-27.

78. Staes CJ, Bennett ST, Evans RS, Narus SP, Huff $\mathrm{SM}$, Sorensen JB. A case for manual entry of structured, coded laboratory data from multiple sources into an ambulatory electronic health record. J Am Med Inform Assoc 2006 Jan-Feb;13(1):12-5.

79. Cowansage CB, Green RA, Kratz A, Vawdrey DK. An application for monitoring order set usage in a commercial electronic health record. AMIA Annu Symp Proc 2012:1184-90.

80. Beeler PE, Bates DW, Hug BL. Clinical decision support systems. Swiss Med Wkly 2014;144:w14073.

81. Iv M, Patel MR, Santos A, Kang YS. Informatics in radiology: use of a macro scripting editor to facilitate transfer of dual-energy X-ray absorptiometry reports into an existing departmental voice recognition dictation system. Radiographics 2011 Jul-Aug;31(4):1181-9.

82. Landman A, Emani S, Carlile N, Rosenthal DI, Semakov S, Pallin DJ, et al. A mobile app for securely capturing and transferring clinical images to the electronic health record: description and preliminary usability study. JMIR MHealth UHealth 2015;3(1):e1.

83. Abramson EL, Patel V, Malhotra S, Pfoh ER, Nena Osorio S, Cheriff A, et al. Physician experiences transitioning between an older versus newer elec- tronic health record for electronic prescribing. Int J Med Inform 2012 Aug;81(8):539-48.

84. Lawlor T, Barrows E. Behavioral health electronic medical record. Psychiatr Clin North Am 2008 Mar;31(1):95-103.

85. Druss BG, Ji X, Glick G, von Esenwein SA. Randomized trial of an electronic personal health record for patients with serious mental illnesses. Am J Psychiatry 2014 Mar;171(3):360-8.

86. Clemens NA. Privacy, consent, and the electronic mental health record: The Person vs. the System. J Psychiatr Pract 2012 Jan;18(1):46-50.

87. Brandeis GH, Hogan M, Murphy M, Murray S. Electronic health record implementation in community nursing homes. J Am Med Dir Assoc 2007 Jan;8(1):31-4.

88. Munyisia E, Yu P, Hailey D. The effect of an electronic health record system on nursing staff time in a nursing home: a longitudinal cohort study. Australas Med J 2014;7(7):285-93.

89. Bercovitz A, Sengupta M, Jamison P. Electronic medical record adoption and use in home health and hospice. NCHS Data Brief 2010 Sep(45):1-8.

90. Blewett DR, Barnett GO, Chueh HC. Experience with an electronic health record for a homeless population. Proc AMIA Symp 1999:481-5.

91. Madison LG, Phillip WR. A case study of user assessment of a corrections electronic health record. Perspect Health Inf Manag 2011;8:1b.

92. Li YC, Lee PS, Jian WS, Kuo CH. Electronic health record goes personal world-wide. Yearb Med Inform 2009:40-3.

93. Iakovidis I. From electronic medical record to personal health records: present situation and trends in European Union in the area of electronic healthcare records. Stud Health Technol Inform 1998;52 Pt 1:suppl 18-22.

94. Baudendistel I, Winkler E, Kamradt M, Brophy S, Langst $\mathrm{G}$, Eckrich $\mathrm{F}$, et al. The patients' active role in managing a personal electronic health record: a qualitative analysis. Support Care Cancer 2015 Sep;23(9):2613-21.

95. Buckley A, Fox S. Know me - a journey in creating a personal electronic health record. Stud Health Technol Inform 2015;208:93-7.

96. Cahill JE, Gilbert MR, Armstrong TS. Personal health records as portal to the electronic medical record. J Neurooncol 2014 Mar;117(1):1-6.

97. Chen ES, Melton GB, Burdick TE, Rosenau PT, Sarkar IN. Characterizing the use and contents of free-text family history comments in the Electronic Health Record. AMIA Annu Symp Proc 2012;2012:85-92

98. Almond H, Cummings E, Turner P. Australia's personally controlled electronic health record and primary healthcare: generating a framework for implementation and evaluation. Stud Health Technol Inform 2013;188:1-6.

99. Greenhalgh T, Hinder S, Stramer K, Bratan T, Russell J. Adoption, non-adoption, and abandonment of a personal electronic health record: case study of HealthSpace. BMJ 2010;341:c5814.

100. Tavakoli N, Isfahani SS, Piri Z, Amini A. Patient access to electronic health record: a comparative study on laws, policies and procedures in selected countries. Med Arch 2013;67(1):63-7.

101. Czaja SJ, Zarcadoolas C, Vaughon WL, Lee CC, Rockoff ML, Levy J. The usability of 
electronic personal health record systems for an underserved adult population. Hum Factors 2015 May;57(3):491-506.

102. Feero WG, Bigley MB, Brinner KM, Family Health History Multi-Stakeholder Workgroup of the American Health Information C. New standards and enhanced utility for family health history information in the electronic health record: an update from the American Health Information Community's Family Health History Multi-Stakeholder Workgroup. J Am Med Inform Assoc 2008 Nov-Dec;15(6):723-8.

103. Tarczy-Hornoch P, Amendola L, Aronson SJ, Garraway L, Gray S, Grundmeier RW, et al. A survey of informatics approaches to whole-exome and whole-genome clinical reporting in the electronic health record. Genet Med 2013 Oct:15(10):824-32.

104. Chen WH, Lu YW, Lai F, Chien YH, Hwu WL. Integrating human genome database into electronic health record with sequence alignment and compression mechanism. J Med Syst 2012 Aug;36(4):2587-97.

105. Marsolo K, Spooner SA. Clinical genomics in the world of the electronic health record. Genet Med 2013 Oct;15(10):786-91.

106. Krishnamoorthy P, Gupta D, Chatterjee S, Huston J, Ryan JJ. A review of the role of electronic health record in genomic research. J Cardiovasc Transl Res 2014 Nov;7(8):692-700.

107. Herr TM, Bielinski SJ, Bottinger E, Brautbar A, Brilliant M, Chute CG, et al. Practical considerations in genomic decision support: The eMERGE experience. J Pathol Inform 2015;6:50.

108. Herr TM, Bielinski SJ, Bottinger E, Brautbar A, Brilliant $\mathrm{M}$, Chute $\mathrm{CG}$, et al. A conceptual model for translating omic data into clinical action. J Pathol Inform 2015;6:46.

109. Pathak J, Kiefer RC, Bielinski SJ, Chute CG. Applying semantic web technologies for phenome-wide scan using an electronic health record linked Biobank. J Biomed Semantics 2012;3(1):10.

110. Gundlapalli AV, Olson J, Smith SP, Baza M, Hausam RR, Eutropius LJ, et al. Hospital electronic medical record-based public health surveillance system deployed during the 2002 Winter Olympic Games. Am J Infect Control 2007 Apr;35(3):163-71.

111. Kukafka R, Ancker JS, Chan C, Chelico J, Khan S, Mortoti S, et al. Redesigning electronic health record systems to support public health. J Biomed Inform 2007 Aug;40(4):398-409.

112. Vogel J, Brown JS, Land T, Platt R, Klompas M. MDPHnet: secure, distributed sharing of electronic health record data for public health surveillance, evaluation, and planning. Am J Public Health 2014 Dec;104(12):2265-70.

113. Berner ES. Diagnostic decision support systems: why aren't they used more and what can we do about it? AMIA Annu Symp Proc 2006:1167-8.

114. Berner ES, Webster GD, Shugerman AA, Jackson JR, Algina J, Baker AL, et al. Performance of four computer-based diagnostic systems. New Engl J Med 1994 Jun 23;330(25):1792-6.

115. Wright A, Sittig DF, Ash JS, Feblowitz J, Meltzer S, McMullen C, et al. Development and evaluation of a comprehensive clinical decision support taxonomy: comparison of front-end tools in commercial and internally developed electronic health record systems. J Am Med Inform Assoc 2011 May 1;18(3):232-42.

116. Evans RS, Carlson R, Johnson KV, Palmer BK, Lloyd JF. Enhanced notification of infusion pump programming errors. Stud Healh Technol Inform 2010;160(Pt 1):734-8.

117. Evans RS, Johnson KV, Flint VB, Kinder T, Lyon CR, Hawley WL, et al. Enhanced notification of critical ventilator events. J Am Med Inform Assoc 2005 Nov-Dec;12(6):589-95.

118. Greenes RA. Clinical Decision Support: The Road to Broad Adoption. London: Elsevier; 2014.

119. Afzal Z, Engelkes M, Verhamme KM, Janssens HM, Sturkenboom MC, Kors JA, et al. Automatic generation of case-detection algorithms to identify children with asthma from large electronic health record databases. Pharmacoepidemiol Drug Saf 2013 Aug;22(8):826-33.

120. Meystre SM, Savova GK, Kipper-Schuler KC, Hurdle JF. Extracting information from textual documents in the electronic health record: a review of recent research. Yearb Med Inform 2008:128-44.

121. Friedman C, Hripcsak G. Natural language processing and its future in medicine. Acad Med 1999 Aug; 74(8):890-5

122. Plazzotta F, Otero C, Luna D, de Quiros FG. Natural language processing and inference rules as strategies for updating problem list in an electronic health record. Stud Health Technol Inform 2013;192:1163.

123. Chen ES, Sarkar IN. Mining the electronic health record for disease knowledge. Methods Mol Biol 2014:1159:269-86

124. Peters SG, Buntrock JD. Big data and the electronic health record. J Ambul Care Manage 2014 Jul-Sep;37(3):206-10.

125. Springman SR. Integration of the enterprise electronic health record and anesthesia information management systems. Anesthesiol Clin 2011 Sep;29(3):455-83.

126. Elevitch FR. SNOMED CT: electronic health record enhances anesthesia patient safety. AANA J 2005 Oct; 73(5):361-6.

127. Krist AH, Beasley JW, Crosson JC, Kibbe DC, Klinkman MS, Lehmann CU, et al. Electronic health record functionality needed to better support primary care. J Am Med Inform Assoc 2014 Sep-Oct;21(5):764-71.

128. Spooner SA, Council on Clinical Information Technology AAoP. Special requirements of electronic health record systems in pediatrics. Pediatrics 2007 Mar;119(3):631-7.

129. Lehmann CU, Council on Clinical Information T. Pediatric aspects of inpatient health information technology systems. Pediatrics 2015 Mar;135(3):e756-68.

130. Lehmann CU, O'Connor KG, Shorte VA, Johnson TD. Use of electronic health record systems by office-based pediatricians. Pediatrics 2015 Jan;135(1):e7-15.

131. Doods J, Botteri F, Dugas M, Fritz F, Ehr4CrWP. A European inventory of common electronic health record data elements for clinical trial feasibility. Trials 2014;15:18.
132. Bastani A, Shaqiri B, Palomba K, Bananno D, Anderson W. An ED scribe program is able to improve throughput time and patient satisfaction. Am J Emerg Med 2014 May;32(5):399-402.

133. Bahensky JA, Jaana M, Ward MM. Health care information technology in rural America: electronic medical record adoption status in meeting the national agenda. J Rural Health 2008 Spring;24(2):101-5.

134. Allen C, Manyika P, Ufitamahoro E, Musabende A, Rich M, Jazayeri D, et al. Expanding an electronic medical record to support community health worker and nutritional support programs in rural Rwanda. AMIA Annu Symp Proc 2007:860.

135. Aminpour F, Sadoughi F, Ahamdi M. Utilization of open source electronic health record around the world: A systematic review. J Res Med Sci 2014 Jan;19(1):57-64.

136. Massaut J, Reper P. Open source electronic health record and patient data management system for intensive care. Stud Health Technol Inform 2008;141:139-45.

137. Fraser HS, Blaya J. Implementing medical information systems in developing countries, what works and what doesn't. AMIA Annu Symp Proc 2010;2010:232-6

138. Flores Zuniga AE, Win KT, Susilo W. Functionalities of free and open electronic health record systems. Int J Technol Assess Health Care 2010 Oct;26(4):382-9.

139. Coats B, Acharya S. Leveraging the cloud for electronic health record access. Perspect Health Inf Manag 2014;11:1g.

140. Schweitzer EJ. Reconciliation of the cloud computing model with US federal electronic health record regulations. JAm Med Inform Assoc 2012 Mar-Apr;19(2):161-5.

141. Horvath MM, Rusincovitch SA, Brinson S, Shang HC, Evans S, Ferranti JM. Modular design, application architecture, and usage of a self-service model for enterprise data delivery: the Duke Enterprise Data Unified Content Explorer (DEDUCE). J Biomed Inform 2014 Dec;52:231-42

142. Evans RS, Lloyd JF, Pierce LA. Clinical use of an enterprise data warehouse. AMIA Annu Symp Proc 2012;2012:189-98.

143. Saleem JJ, Russ AL, Justice CF, Hagg H, Ebright PR, Woodbridge PA, et al. Exploring the persistence of paper with the electronic health record. Int J Med Inform 2009 Sep; 78(9):618-28.

144. Flanagan ME, Saleem JJ, Millitello LG, Russ AL, Doebbeling BN. Paper- and computer-based workarounds to electronic health record use at three benchmark institutions. J Am Med Inform Assoc 2013 Jun;20(e1):e59-66.

145. Darmon D, Sauvant R, Staccini P, Letrilliart L. Which functionalities are available in the electronic health record systems used by French general practitioners? An assessment study of 15 systems. Int J Med Inform 2014 Jan;83(1):37-46.

146. Krist AH. Electronic health record innovations for healthier patients and happier doctors. Journal of the American Board of Family Medicine : JABFM. 2015 May-Jun;28(3):299-302.

147. Shoolin J, Ozeran L, Hamann C, Bria W, 2nd. Association of Medical Directors of Informa- 
tion Systems consensus on inpatient electronic health record documentation. Appl Clin Inform 2013;4(2):293-303.

148. Bowman S. Impact of electronic health record systems on information integrity: quality and safety implications. Perspect Health Inf Manag 2013;10:1c.

149. Middleton B, Bloomrosen M, Dente MA, Hashmat B, Koppel R, Overhage JM, et al. Enhancing patient safety and quality of care by improving the usability of electronic health record systems: recommendations from AMIA. J Am Med Inform Assoc 2013 Jun;20(e1):e2-8.

150. Cresswell KM, Worth A, Sheikh A. Integration of a nationally procured electronic health record system into user work practices. BMC Med Inform Decis Mak 2012;12:15.

151. Koppel R, Kreda DA. Healthcare IT usability and suitability for clinical needs: challenges of design, workflow, and contractual relations. Stud Health Technol Inform 2010;157:7-14.

152. Elrod J, Androwich IM. Applying human factors analysis to the design of the electronic health record. Stud Health Technol Inform 2009;146:132-6.

153. Singh H, Classen DC, Sittig DF. Creating an oversight infrastructure for electronic health record-related patient safety hazards. J Patient Saf 2011 Dec;7(4):169-74.

154. Ellaway RH, Graves L, Greene PS. Medical education in an electronic health record-mediated world. Med Teach 2013 Apr;35(4):282-6.

155. Elliott K, Judd T, McColl G. A student-centred electronic health record system for clinical education. Stud Health Technol Inform 2011;168:57-64.

156. Mohan V, Hersh WR. Development and evaluation of an electronic health record configuration and customization laboratory course for clinical informatics students. Stud Health Technol Inform 2013; 192:1122.

157. Borbolla D, Gorman P, Del Fiol G, Mohan V, Hersh W, Otero C, et al. Physicians perceptions of an educational support system integrated into an electronic health record. Stud Health Technol Inform 2013;186:125-9.

158. Borycki EM, Kushniruk AW, Joe R, Armstrong B, Otto T, Ho K, et al. The University of Victoria Interdisciplinary Electronic Health Record Educational Portal. Stud Health Technol Inform 2009;143:49-54

159. Landman AB, Redden L, Neri P, Poole S, Horsky $\mathrm{J}$, Raja AS, et al. Using a medical simulation center as an electronic health record usability laboratory. J Am Med Inform Assoc 2014 MayJun;21(3):558-63.

160. March CA, Steiger D, Scholl G, Mohan V, Hersh WR, Gold JA. Use of simulation to assess electronic health record safety in the intensive care unit: a pilot study. BMJ Open 2013;3(4).

161. Vuk J, Anders ME, Mercado CC, Kennedy RL, Casella J, Steelman SC. Impact of simulation training on self-efficacy of outpatient health care providers to use electronic health records. Int J Med Inform 2015 Jun;84(6):423-9.

162. Borycki EM, Kushniruk AW, Kuwata S, Kannry $J$. Engineering the electronic health record for safety: a multi-level video-based approach to diagnosing and preventing technology-induced error arising from usability problems. Stud Health Technol Inform 2011;166:197-205.

163. Hersh WR, Gorman PN, Biagioli FE, Mohan $\mathrm{V}$, Gold JA, Mejicano GC. Beyond information retrieval and electronic health record use: competencies in clinical informatics for medical education. Adv Med Educ Pract 2014;5:205-12.

164. Humphreys BL. Electronic health record meets digital library: a new environment for achieving an old goal. J Am Med Inform Assoc 2000 SepOct;7(5):444-52.

165. Albert KM. Integrating knowledge-based resources into the electronic health record: history, current status, and role of librarians. Med Ref Serv Q 2007 Fall;26(3):1-19.

166. Cimino JJ, Jing X, Del Fiol G. Meeting the electronic health record "meaningful use" criterion for the HL7 infobutton standard using OpenInfobutton and the Librarian Infobutton Tailoring Environment (LITE). AMIA Annu Symp Proc 2012;2012:112-20.

167. Del Fiol G, Curtis C, Cimino JJ, Iskander A, Kalluri AS, Jing X, et al. Disseminating context-specific access to online knowledge resources within electronic health record systems. Stud Health Technol Inform 2013;192:672-6.

168. McDonald C, Tang, P.C., Hripcsak, G. Electronic Health Record Systems. In: Shorliffe EH, Cimino JJ, editors. Biomedical Informatics: Computer Applications in Health Care and Biomedicine. 4 ed. New York, NY:: Springer-Verlag; 2014. p. 391-421.

169. McDonald CJ, Tierney WM. Computer-stored medical records. Their future role in medical practice. JAMA 1988 Jun 17;259(23):3433-40.

170. Lindberg $\mathrm{C}$. The national networks--present and future. J AHIM $1993 \mathrm{Feb} ; 64(2): 59-60$.

171. Ceusters W, De Moor G, Bonneu R, Schilders L. Training of health care personnel towards the implementation and use of electronic health care records using integrated imaging technology. Medical Inform (Lond) 1992 OctDec;17(4):215-23.

172. England SP. One positive impact of health care reform to physicians: the computer-based patient record. Top Health Inf Manage 1993 Nov; $14(2): 38-47$

173. Adler-Milstein J, Furukawa MF, King J, Jha AK. Early results from the hospital Electronic Health Record Incentive Programs. Am J Manag Care $2013 \mathrm{Jul} ; 19(7):$ e273-84.

174. Rector AL, Nowlan WA, Kay S. Foundations for an electronic medical record. Methods Inf Med 1991 Aug;30(3):179-86.

175. Essin DJ. Intelligent processing of loosely structured documents as a strategy for organizing electronic health care records. Methods Inf Med 1993 Aug;32(4):265-8.

176. Miller C. The electronic medical record: a definition and discussion. Topics Health Inf Manage $1993 \mathrm{Feb} ; 13(3): 20-9$.

177. Benson DS, Reimlinger G. Electronic medical records in the ambulatory setting: the quality edge. J Ambul Care Manage1991 Jan;14(1):78-87.

178. Ancker JS, Kern LM, Edwards A, Nosal S, Stein DM, Hauser D, et al. Associations between healthcare quality and use of electronic health record functions in ambulatory care. J Am Med Infom Med Assoc 2015 Apr 20.

179. Burns J. Product specification: the fifth discipline of health care. Manag Care Q 1993 Autumn;1(4):29-33.

180. Modai I, Rabinowitz J. Why and how to establish a computerized system for psychiatric case records. Hosp Community Psychiatry 1993 Nov;44(11):1091-5

181. Peters DF, Fitzpatrick KT. Automating the medical practice--promise and peril. Physician Assist 1993 Sep;17(9):91-4, 97.

182. Harrington J. The networking standards evolution: toward a real electronic medical record. Interview by Carolyn Dunbar. Comput Healthc $1990 \mathrm{Feb} ; 11(2): 18-21$.

183. Feste LK. Electronic signature--as it is today. J AHIMA 1993 Apr;64(4):18-9.

184. Cimino JJ. Improving the electronic health record--are clinicians getting what they wished for? JAMA. 2013 Mar 13;309(10):991-2.

185. Ober KP, Applegate WB. The electronic health record. Are we the tools of our tools? The Pharos Alpha Omega Alpha Honor Med Soc 2015 Winter;78(1):8-14.

186. Broverman CA, Schlesinger JM, Sperzel WD, Kapusnik-Uner J. The future of knowledge-based components in the electronic health record. Stud Health Technol Inform 1998;52 Pt 1:457-61.

187. Baron RJ. Quality improvement with an electronic health record: achievable, but not automatic. Ann Intern Med 2007 Oct 16;147(8):549-52.

188. Silverman H, Ho YX, Kaib S, Ellis WD, Moffitt MP, Chen Q, et al. A novel approach to supporting relationship-centered care through electronic health record ergonomic training in preclerkship medical education. Acad Med 2014 Sep;89(9):1230-4.

189. Senathirajah Y, Bakken S, Kaufman D. The clinician in the Driver's Seat: part 1 - a drag/ drop user-composable electronic health record platform. J Biomed Inform 2014 Dec;52:165-76.

190. Grabenbauer L, Skinner A, Windle J. Electronic Health Record Adoption - Maybe It's not about the Money: Physician Super-Users, Electronic Health Records and Patient Care. Appl Clin Inform 2011;2(4):460-71

191. Bell PD. Standards and the integrated electronic health care record. Health Care Manag 2000 Sep;19(1):39-43.

192. Abramson EL, McGinnis S, Edwards A, Maniccia DM, Moore J, Kaushal R, et al. Electronic health record adoption and health information exchange among hospitals in New York State. J Eval Clin Pract 2012 Dec;18(6):1156-62.

193. Bruun-Rasmussen M, Bernstein K, Vingtoft S, Nohr C, Andersen SK. Quality labelling and certification of electronic health record systems. Stud Health Technol Inform 2005;116:47-52.

194. Zhang M, Velasco FT, Musser RC, Kawamoto $\mathrm{K}$. Enabling cross-platform clinical decision support through Web-based decision support in commercial electronic health record systems: proposal and evaluation of initial prototype implementations. AMIA Annu Symp Proc 2013:2013:1558-67.

195. Bosl W, Mandel J, Jonikas M, Ramoni RB, Ko- 
hane IS, Mandl KD. Scalable decision support at the point of care: a substitutable electronic health record app for monitoring medication adherence. Interact J Med Res 2013;2(2):e13.

196. Kho AN, Rasmussen LV, Connolly JJ, Peissig PL, Starren J, Hakonarson H, et al. Practical challenges in integrating genomic data into the electronic health record. Genet Med 2013 Oct:15(10):772-8.

197. Kohane IS. HEALTH CARE POLICY. Ten things we have to do to achieve precision medicine. Science 2015 Jul 3;349(6243):37-8.

198. Ross MK, Wei W, Ohno-Machado L. "Big data" and the electronic health record. Yearb Med Inform 2014;9(1):97-104.

199. West VL, Borland D, Hammond WE. Innovative information visualization of electronic health record data: a systematic review. J Am Med Inform Assoc 2015 Mar;22(2):330-9.

200. Hsu W, Taira RK, El-Saden S, Kangarloo H, Bui AA. Context-based electronic health record: toward patient specific healthcare. IEEE Trans Inf Technol Biomed 2012 Mar;16(2):228-34.

201. Haux R, Knaup P, Leiner F. On educating about medical data management - the other side of the electronic health record. Methods Inf Med 2007;46(1):74-9.

202. Ancker JS, Kern LM, Edwards A, Nosal S, Stein DM, Hauser D, et al. How is the electronic health record being used? Use of EHR data to assess physician-level variability in technology use. J Am Med Inform Assoc 2014 Nov-Dec;21(6):1001-8.

203. Mandl KD, Mandel JC, Kohane IS. Driving Innovation in Health Systems through an AppsBased Information Economy. Cell Syst 2015 Jul;1(1):8-13.

204. Meeks DW, Smith MW, Taylor L, Sittig DF, Scott JM, Singh H. An analysis of electronic health record-related patient safety concerns. JAm Med Inform Assoc 2014 Nov-Dec;21(6):1053-9.

205. Bailey LC, Milov DE, Kelleher K, Kahn MG, Del Beccaro M, Yu F, et al. Multi-Institutional Sharing of Electronic Health Record Data to Assess Childhood Obesity. PloS One. 2013;8(6):e66192.

206. Li YC, Detmer DE, Shabbir SA, Nguyen PA, Jian WS, Mihalas GI, et al. A global travelers' electronic health record template standard for personal health records. JAm Med Inform Assoc 2012 Jan-Feb;19(1):134-6.

207. Zangara G, Corso PP, Cangemi F, Millonzi F, Collova F, Scarlatella A. A cloud based architecture to support Electronic Health Record. Stud Health Technol Inform 2014;207:380-9.

208. Hanauer DA, Preib R, Zheng K, Choi SW Patient-initiated electronic health record amendment requests. J Am Med Inform Assoc 2014 Nov-Dec;21(6):992-1000.

209. Kalra D. Electronic health record standards. Yearb Med Inform 2006:136-44.
210. Bouhaddou O, Bennett J, Teal J, Pugh M, Sands M, Fontaine F, et al. Toward a Virtual Lifetime Electronic Record: the Department of Veterans Affairs experience with the Nationwide Health Information Network. AMIA Annu Symp Proc 2012;2012:51-60.

211. Andrews L, Gajanayake R, Sahama T. The Australian general public's perceptions of having a personally controlled electronic health record (PCEHR). Int J Med Inform 2014 Dec:83(12):889-900.

212. Friedman C, Rubin J, Brown J, Buntin M, Corn M, Etheredge L, et al. Toward a science of learning systems: a research agenda for the high-functioning Learning Health System. J Am Med Inform Assoc 2015 Jan;22(1):43-50.

Correspondence to:

R. Scott Evans, MS, PhD, FACMI

Department of Medical Informatics

LDS Hospital

$8^{\text {th }}$ Ave \& C Street

Salt Lake City, Utah 84143

USA

Tel: +1801 408-3029

Fax: + 1801 408-5802

E-mail: rscott.evans@imail.org 